The Regional Economics Applications Laboratory (REAL) is a cooperative venture between the University of Illinois and the Federal Reserve Bank of Chicago focusing on the development and use of analytical models for urban and regional economic development. The purpose of the Discussion Papers is to circulate intermediate and final results of this research among readers within and outside REAL. The opinions and conclusions expressed in the papers are those of the authors and do not necessarily represent those of the Federal Reserve Bank of Chicago, Federal Reserve Board of Governors or the University of Illinois. All requests and comments should be directed to Geoffrey J. D. Hewings, Director, Regional Economics Applications Laboratory, 607 South Mathews, Urbana, IL, 61801-3671, phone (217) 333-4740, FAX (217) 244-9339.

Web page: www.uiuc.edu/unit/real

$$
\begin{aligned}
& \text { Discussion } \\
& \text { Paper }
\end{aligned}
$$

REGIONAL CONVERGENCE AND THE IMPACT OF EUROPEAN STRUCTURAL FUNDS OVER 1989-1999: A SPATIAL ECONOMETRIC ANALYSIS

by

Sandy Dall'erba and Julie Le Gallo

REAL 03-T-XX

March, 2003 
First draft: do not quote

\title{
REGIONAL CONVERGENCE AND THE IMPACT OF EUROPEAN STRUCTURAL FUNDS OVER 1989-1999: \\ A SPATIAL ECONOMETRIC ANALySIS
}

\author{
Sandy Dall'erba \\ CATT, Université de Pau (France) and \\ REAL \\ University of Illinois at Urbana-Champaign \\ 220 Davenport Hall, 607 S. Mathews Av. \\ Urbana, IL 61801-3671 \\ USA \\ dallerba@uiuc.edu
}

and

\section{Julie Le Gallo}

REAL

University of Illinois at Urbana-Champaign

220 Davenport Hall, 607 S. Mathews Av.

Urbana, IL 61801-3671

USA

jlegallo@uiuc.edu

March 2003 


\title{
REGIONAL CONVERGENCE AND THE IMPACT OF EUROPEAN STRUCTURAL FUNDS OVER 1989-1999: A SPatial ECONOMETRIC ANAlysis
}

\begin{abstract}
The aim of this paper is to assess the impact of structural funds on the convergence process of 145 European regions over 1989-1999. With the aim of enhancing cohesion, these funds are primarily allocated to the least developed regions. The most important part of these funds is devoted to transportation infrastructures, which induce strong spillover effects. However they do not necessarily contribute to a more even regional development. Their impact has therefore to be seen in the light of growth rate variations of the targeted region and of the whole sample. Using the formal tools of spatial econometrics, we first detect strong evidence of spatial autocorrelation in the distribution of per capita GDP. Moreover, two clusters, representative of the core-periphery framework, are persistent over the period and highlight spatial heterogeneity. These spatial effects are then included in the estimation of an appropriate conditional $\beta$-convergence model, which allows us to control for spatial spillover effects among regions. Finally, with this model, simulation experiments assess the impact of shocks proportional to per capita structural funds first on the growth rate of the targeted region and second on the growth rate of all the regions of our sample. The results show that structural funds have positively benefited to the growth of the targeted regions, but that growth in the least developed regions suffer from the small extent of regional spillover effects.
\end{abstract}

Keywords: European regions, structural funds, $\beta$-convergence, spatial econometrics, geographic spillovers

JEL Classification: C14, O52, R11, R15 


\section{Section 1 Introduction}

The phenomenon of persistent income disparities among European regions has been widely studied in the literature, using convergence models most of the time based on neoclassical specifications. The results of empirical estimations reveal greater cohesion among European regions (Barro and Sala-I-Martin, 1991; Amstrong, 1995), but increasing disparities among regions within countries (Esteban, 1994; Neven and Gouyette, 1995; Quah, 1996). Instead of a catching-up of the poorest regions, European integration seems to have benefited mainly to the richest regions in the poorest countries.

However, the majority of these empirical tests of regional income convergence are based on the same assumptions as the ones underlying for international income convergence: regions are considered as isolated entities, as if their geographical location and potential interregional linkages did not matter. Only recently, the role of spatial effects has been considered in empirical works using the formal tools of spatial statistics and econometrics. For the European regions, papers in this area include Fingleton (1999, 2001, 2003), Maurseth (2001), Bivand and Brunstad (2002) or Le Gallo et al. (2003). The underlying idea is that forces driving to relocation/agglomeration process and hence to even/uneven regional development such as productivity (Lopez-Bazo et al., 1999), transportation infrastructures (Krugman and Venables, 1995, 1996), technology and knowledge spillovers (Martin and Ottaviano, 1999), factor mobility (Krugman, 1991a, b; Puga, 1999), have explicit geographic components. The first purpose of this paper is therefore to include spatial effects in the estimation of the GDP convergence process among 145 European regions over 1989-1999.

Once the appropriate convergence model has been selected, spatial correlation in the residuals means that a random shock in a given region propagates to all regions of the sample. The second objective of this paper is then to estimate the impact of a shock in a given region on its own development and on the development on its neighboring regions. Le Gallo et al. 
(2003) have already simulated the spatial diffusion of a shock on neighboring regions. They find that the strength of diffusion depend on the economic dynamism and on the spatial location of the targeted region. In this paper, we simulate these spillover effects as well, but we extend the analysis to 1999 , and include the real values of structural funds over 19891999. Structural funds are the most important instrument of the European regional development policy (which amounted for 247 billion Ecus over 1989-1999, i.e. one-third of the Community budget). The implementation of structural funds induces strong spatial externalities since they mainly finance public infrastructures. For instance, when they finance transportation infrastructures that come to a decrease in transportation costs, it may also affect the process of industry location. As a result, structural funds do not systematically benefit to the long-run growth of the region where they are implemented (Vickerman et al., 1999; Venables and Gasiorek, 1999; Dall'erba, 2003a). The existence of these externalities makes the impact of regional funds harder to estimate. In the absence of details on the sectoral allocation of structural funds for each region, this paper considers structural funds as a public capital acting directly on the regional growth rate. To our knowledge, this paper is the first one to analyze shocks proportional to the real value of per capita structural funds and their impact not only on the targeted regions but also on all the European regions.

This paper proceeds as follows: section 2 gives an overview of recent theoretical and empirical studies on the impact of regional assistance on uneven development. Section 3 provides some insights into the $\beta$-convergence model and spatial effects upon which the empirical estimation described in the following sections relies. In section 4 we present the data and use spatial analysis tools to detect spatial autocorrelation as well as spatial heterogeneity among European regional GDP. The appropriate convergence model including these spatial effects is then described. In this model, spatial correlation in the residuals 
implies that a shock in a given region propagates to all regions of the sample. Therefore, section 5 estimates the impact of shocks, based on the real values of structural funds, on the growth rate of an assisted region as well as on the growth rate of all the regions of our sample. Section 6 concludes and gives some comments on the allocation of the European structural funds.

\section{Section 2 Impact of Regional Assistance on Uneven Development}

The European Commission considers large regional imbalances unacceptable on distributional and political grounds. The successive enlargements of the European Community to the peripheral and less developed countries have made disparities in infrastructure endowments and per capita incomes so obvious (see figure $1^{1}$ ) that $68 \%$ of structural funds are devoted to the least developed regions (i.e. objective 1 regions having a per capita GDP below $75 \%$ of the European average). Structural funds are the most important instruments of the European regional development policy with 247 billion Ecus over 19891999. In addition, the four least developed countries (Spain, Portugal, Ireland and Greece which had a per capita GNP below $90 \%$ of the EU average over 1989-1999) benefited from almost 17 billion Ecus allocated as cohesion funds. Figure 2 displays the distribution of structural funds during the 1989-1999 period. As expected, the poor and peripheral regions are the ones that benefited at most from Community support.

$$
<<\text { Insert figures } 1 \text { and } 2 \text { here }>>
$$

Four input-output models are used by the European Commission to assess the impact of structural funds on the four least developed countries (see the Sixth Periodic Report on the

\footnotetext{
${ }^{1}$ All figures have been realized using Arcview GIS 3.2 (Esri).
} 
Social and Economic Situation and Development of the Regions of the Community, 1999).

Their results lead to the conclusion that structural funds have had a significant effect in reducing disparities in economic performance across the Union and succeeded in narrowing the gap in GDP per head between the four Cohesion countries and the rest of the Union. Several empirical studies confirm the catching-up of cohesion countries in terms of per capita GNP (Esteban, 1994; Neven and Gouyette, 1995; Quah, 1996; and more recently Martin, 1999; and Dall'erba and Hewings, 2003). However, these studies also reveal increasing regional disparities within these countries (but Greece). Therefore, a reconsideration of the impact of these funds on regional development is necessary.

Theoretical analyses show that their impact on regional development is ambiguous. For Aschauer (1989) and Barro (1990), public infrastructures are an input in the production function. Therefore, then policies financing new public infrastructures increase the marginal product of private capital, fostering capital accumulation and growth. However, when such investments finance transportation infrastructures that yield to a decrease in transportation costs, it may affect the process of industry location. As a result, they do not systematically benefit the region where they are implemented (Martin P., 2000; Vickerman, 1996). With respectively $30 \%$ and $60 \%$ of structural and cohesion funds devoted to transportation sectors, their impact on regional development has to be seen in the light of characteristics of the transportation sector. The empirical study of Vickerman et al. (1999) points out that new transportation infrastructures tend to be built within or between core regions, where the demand in this sector is the highest. In other words, the European transportation network is more and more composed of hub-and-spoke interconnections. Puga and Venables (1997) show that this kind of network promotes agglomeration in the hub. Firms located in the hub face lower transaction costs in trading with firms in spoke locations than a firm in any spoke 
location trading with a firm in another spoke. The authors add that this network favors disparities between spoke regions.

For Venables and Gasiorek (1999), recent developments in the Iberian transportation network have reinforced the place of Madrid as a central location through which traffic traveling from one edge of the peninsula to another has to pass. The Madrid Ring road which connects the most important Spanish highways to each other has strongly contributed to it. In terms of regional development, it does not mean that peripheral regions do not benefit of the new network, but the gains in accessibility will always be higher in the core region (Vickerman et al., 1999). In their study, Venables and Gasiorek (1999) also estimate the impact of a new bridge, called Tagus Crossing, in Lisboã. Their results show that building new transportation infrastructures within a peripheral region acts as a public infrastructure capital within the region itself, but has very low spillover effects outside the region. That is why intraregional transportation infrastructures do not necessarily promote the aggregate growth, even if they may favor local development. On the other hand, promoting the aggregate growth through interregional transportation infrastructures mainly benefits the core region (Martin, 2000). Transportation infrastructures thus cannot always be seen as an efficient instrument to reduce interregional disparities. The next section will introduce the $\beta$-convergence model and spatial effects upon which we will assess the impact of structural funds on the regional growth rate.

\section{Section $3 \beta$-convergence models and spatial effects}

Since the publication of the seminal articles of Barro and Sala-i-Martin (1991, 1992, 1995), numerous studies have examined the $\beta$-convergence hypothesis ${ }^{2}$. This concept is linked to the neoclassical growth model, which predicts that the growth rate of a region is

\footnotetext{
${ }^{2}$ See Durlauf and Quah (1999) for a review of this extensive literature.
} 
positively related to the distance that separates it from its steady-state. Empirical evidence for $\beta$-convergence has usually been investigated by regressing growth rates of GDP on initial levels.

If all economies are structurally identical and have access to the same technology, they are then characterized by the same steady state, and differ only by their initial conditions. This is the concept known as unconditional or absolute $\beta$-convergence. It is only in that case that the prediction of the neoclassical growth model holds: poor economies grow faster than rich ones and eventually catch them up in the long run. The hypothesis of unconditional $\beta$-convergence is usually tested on the following cross-sectional model, in matrix form:

$$
g_{T}=\alpha S+\beta y_{0}+\varepsilon \quad \varepsilon \sim N\left(0, \sigma_{\varepsilon}^{2} I\right)
$$

where $g_{T}$ is the $(n \times 1)$ vector of average growth rates of per capita GDP between date 0 and $T$; $S$ is the $(n \times 1)$ sum vector; $y_{0}$ is the vector of log per capita GDP levels at date 0 . There is unconditional $\beta$-convergence when the estimate of $\beta$ is significantly negative.

Relaxing the assumption of similar steady-states yields to the concept of conditional $\beta$-convergence. Note, in this case, that if economies have different steady states, this concept is compatible with a persistent high degree of inequality among economies. It is usually tested on the following cross-sectional model:

$$
g_{T}=\alpha S+\beta y_{0}+X \phi+\varepsilon \quad \varepsilon \sim N\left(0, \sigma_{\varepsilon}^{2} I\right)
$$

with the same notations as above and $X$ is a matrix of variables, maintaining constant the steady state of each economy. There is conditional $\beta$-convergence if the estimate of $\beta$ is significantly negative once $X$ is held constant.

The convergence process is traditionally characterized by its convergence speed and its half-life, which can be recovered using the estimated $\beta$ coefficient in equations (1) or (2). 
The convergence speed is $b=-\ln (1+T \beta) / T$. The time necessary for the economies to fill half of the variation, which separates them from their steady state, is called the half-life: $\tau=-\ln (2) / \ln (1+\beta)$.

Both $\beta$-convergence concepts have been heavily criticized both on theoretical and methodological grounds. For example, Friedman (1992) and Quah (1993) show that $\beta$ convergence tests may be plagued by Galton's fallacy of regression toward the mean. Furthermore, they face several methodological problems such as heterogeneity, endogeneity, and measurement problems (Durlauf and Quah, 1999; Temple, 1999). In this paper, we want to point out the fact that most empirical studies do not take into account the spatial dimension of data. In particular, we investigate the usefulness of two different spatial effects: spatial autocorrelation and spatial heterogeneity.

Spatial autocorrelation refers to the coincidence of attribute similarity and locational similarity (Anselin, 1988, 2001). Applied to the study of income disparities, spatial autocorrelation means that rich regions tend to be geographically clustered as well as poor regions. Although spatial concentration of economic activities in European regions has already been documented (Lopez-Bazo et al., 1999, Le Gallo and Ertur, 2003; Dall'erba, $2003 \mathrm{~b}$ ), most $\beta$-convergence studies do not take into account spatial interdependence between regions $^{3}$. Indeed, as first pointed out by De Long and Summers (1991) and later by Mankiw (1995) and Quah (1996), $\beta$ - and $\sigma$-convergence treat regions as if they were "isolated islands". At the regional scale, though, spatial effects and particularly spatial autocorrelation cannot be neglected in the analysis of convergence processes: several factors, such as trade between

\footnotetext{
${ }^{3}$ Exceptions include the following papers: Armstrong (1995), Moreno and Trehan (1997), Fingleton (1999, 2001), Rey and Montouri (1999), Baumont et al (2003), Le Gallo et al. (2003).
} 
regions, technology and knowledge diffusion, and more generally regional spillovers, may lead to geographically dependent regions.

Integrating spatial autocorrelation into $\beta$-convergence models is useful for three reasons. First, from an econometric point of view, the independence hypothesis on the error may be very restrictive and should be tested since, if it is rejected, the statistical inference based on OLS is not reliable. Second, it allows capturing geographic spillover effects between European regions. This is carried out with the estimation of different spatial econometric models: the spatial lag model, the spatial error model or the spatial crossregressive model (Rey and Montouri, 1999; Le Gallo et al., 2003). Third, spatial autocorrelation allows accounting for variations in the dependent variable arising from latent or unobservable variables. Indeed, in the case of $\beta$-convergence models, the appropriate choice of these explanatory variables may be problematic because we can't be sure conceptually to include all the variables differentiating steady states ${ }^{4}$. Furthermore, in both cases, data on some of these explanatory variables may not be easily accessible and/or reliable for international comparisons (Fingleton 1999). Spatial autocorrelation may therefore act as a proxy to all these omitted variables and catch their effects. This is particularly useful in the case of European data, where explanatory variables are scarce.

Spatial heterogeneity means that economic behaviors are not stable over space. In a regression model, spatial heterogeneity can be reflected by varying coefficients, i.e. structural instability, or by varying error variances across observations, i.e. heteroskedasticity. These variations follow for example specific geographical patterns such as East and West, or North and South. Such a spatial heterogeneity may characterize patterns of economic development

\footnotetext{
${ }^{4}$ More than 90 of such variables have been included in cross-country regressions using international datasets (Durlauf and Quah, 1999)
} 
under the form of spatial regimes and/or groupwise heteroskedasticity: a cluster of rich regions (the core) being distinguished from a cluster of poor regions (the periphery).

Note that this effect can be linked to the concept of convergence clubs (Durlauf and Jonhson, 1995). In case of conditional convergence, equilibrium differs by economy, and each economy approaches its own but unique, globally stable, steady state equilibrium. On the contrary, the concept of club convergence is characterized by the possibility of multiple, locally stable, steady state equilibria. Which of these different equilibria an economy will be reaching depends on the range to which its initial conditions belong. Therefore, a convergence club is a group of economies whose initial conditions are near enough to converge toward the same long-term equilibrium. When convergence clubs exist, one convergence equation should be estimated per club. The question is then on how to determine those clubs. Some authors select a priori criteria, like the belonging to a geographic zone (Baumol, 1986) or some GDP per capita cut-offs (Durlauf and Johnson, 1995). Others prefer to use endogenous methods, as for example, polynomial functions (Chatterji, 1992) or regression trees (Durlauf and Johnson, 1995; Berthélemy and Varoudakis, 1996). In the context of regional economies characterized by strong geographic patterns, like the coreperiphery pattern, spatial convergence clubs can be detected, i.e. clubs that are determined by geographic criteria (Baumont et al., 2003). The following section will illustrate the use and interpretation of spatial autocorrelation and spatial heterogeneity in the context of $\beta$ convergence models. 


\section{Section 4 The convergence process between European regions over 1989-1999}

\subsection{Data}

The regional per capita GDP series are drawn out the most recent version of the NewCronos Regio database by Eurostat. This is the official database used by the European Commission for its evaluation of regional convergence. We first use the logarithms of the per capita GDP of each region over the 1989-1999 period. Our sample is composed of 145 regions at NUTS II level (Nomenclature of Territorial Units for Statistics) over 12 EU countries:

- Belgium: 11 regions

- Denmark: 1 region

- Germany: 30 regions. Berlin and the nine former East German regions are excluded due to historical reasons.

- Greece: 13 regions

- Spain: 16 regions, as we exclude the remote islands: Las Palmas, Santa Cruz de Tenerife Canary Islands and Ceuta y Mellila.

- France: 22 regions

- Ireland: 2 regions

- Italy: 20 regions

- Netherlands: 12 regions. The per capita GDP of Groningen was exceptionally high in 1980 because all the North Sea oil revenues were attributed to this region until 1985. We therefore use the mean growth rate over 1980-1985 to calculate the data over 1980-1988, this last date being the first year were none oil income was systematically attributed to Groningen. 
- Portugal: 5 regions. The Azores and Madeira are excluded because of their geographical distance.

- United Kingdom: 12 regions. In the case of the UK, we use regions at the NUTS I level, because NUTS II regions are not used as governmental units, they are merely statistical inventions of the EU Commission and the UK government.

- Luxembourg: 1 region

We do not include Austria, Finland and Sweden in the study, as we want to focus on the impact of structural assistance over 1989-1999. These three countries joined the EU only in 1995, which means that they did not have access to any regional fund prior to membership. The data on structural funds come from the publications of the Commission. The period under study covers the two first programming periods: the data over 1989-1993 are from "Community structural interventions", Statistical report $n^{\circ} 3$ and 4,(July and Dec. 1992) ${ }^{5}$ and for 1994-1999, from The $11^{\text {th }}$ annual report on the structural funds. These last data are the total payments over the 1994-1999 period plus the commitments taken during this period, but that have not yet been paid.

We are aware that our empirical results could be affected by missing regions and by the use of different levels of spatial aggregation. The choice of the spatial aggregation and identification of the data influence the magnitude of various measures of association. In the literature, this problem is referred as the modifiable areal unit problem (MAUP) (Arbia, 1989; Anselin and Cho, 2000). Moreover, per capita growth in open formal NUTS II regions may reflect characteristics of neighboring regions. Boldrin and Canova (2001) illustrate this problem linked to measuring a variable on a territorial unit artificially defined in which people are free to move. They give the example of the city of Hamburg, which is a NUTS II level

5 The authors would like to thank Jacky Fayolle and Anne Lecuyer for providing this dataset. 
region with high per capita income, but half the population of the whole Hamburg metropolitan area lives in the nearby NUTS II level regions of Schleswig-Holstein and Lower Saxony, commuting to Hamburg for work. As a result, the value added in Hamburg is overstated by $20 \%$ relative to its effective population, while those of Schleswig-Holstein (value added equals $102 \%$ of EU average) and Lower Saxony (104\%) are understated. This is similar for Ile-de-France (160\%) and Bassin Parisien (92.7\%), Communidad de Madrid (101\%) and its neighboring Castillas (66 and 76\%). The choice of studying European regions at the NUTS II level is purely based on regional development policy consideration. This scale level corresponds to the one used to allocate structural funds under objective 1 (around $70 \%$ of structural funds are objective 1).

\subsection{Determination of the Spatial Weight Matrices}

Before going further in the spatial analysis of regional GDP distribution, let's present the construction of the spatial weight matrix, on which all the following analyses rely. In the European context, the existence of islands doesn't allow considering simple contiguity matrices, otherwise the weight matrix would include rows and columns with only zeros for the islands. Since unconnected observations are eliminated from the results of the global statistics, this would change the sample size and the interpretation of the statistical inference. Following the recommendations of Anselin (1996) and Anselin and Bera (1998), we choose

to base them on pure geographical distance, as exogeneity of geographical distance is unambiguous. More precisely, we use the great circle distance between regional centroids. The great distance circle allows to consider that the relevant direction of the dependence can take place in every direction. 
Distance-based weight matrices are defined as:

$$
\left\{\begin{array}{l}
w_{i j}^{*}(k)=0 \text { if } i=j, \forall k \\
w_{i j}^{*}(k)=1 / d_{i j}^{2} \text { if } d_{i j} \leq D(k) \text { and } w_{i j}=w_{i j}^{*} / \sum_{j} w_{i j}^{*} \quad \text { for } k=1, \ldots 3 \\
w_{i j}^{*}(k)=0 \text { if } d_{i j}>D(k)
\end{array}\right.
$$

where $w_{i j}^{*}$ is an element of the unstandardized weight matrix; $w_{i j}$ is an element of the standardized weight matrix; $d_{i j}$ is the great circle distance between centroids of region $i$ and $j$; $D(1)=Q 1, D(2)=M e$ and $D(3)=Q 3, Q 1, M e$ and $Q 3$ are respectively the lower quartile, the median and the upper quartile of the great circle distance distribution. $D(k)$ is the cutoff parameter for $k=1, \ldots 3$ above which interactions are assumed negligible. We use the inverse of the squared distance, in order to reflect a gravity function. Each matrix is row standardized so that it is relative and not absolute distance which matters.

The robustness of the results is also tested by using other weight matrices based on the $k$-nearest neighbors. It is worth mentioning that in the European context, the minimum number of nearest neighbors that guarantees international connections between regions is $k=7$, otherwise the Greek regions would not be linked to Italy at all. Moreover, with is $k=10$, Ireland is connected to the UK, which in turn is connected to the whole continent; and the islands of Sicilia, Sardegna, Corsica are connected to the continental French regions. When the number of $k$-nearest neighbors increases, the share of international interconnections increases as well. We therefore consider $k=10,15,20,25$ neighbors. Finally, three distance contiguity matrices are built according to the critical cut-off previously defined.

\subsection{Estimation Results}

Using the spatial weight matrices previously described, the first step of our analysis is to estimate the presence of spatial effects in the distribution of regional per capita GDPs. In 
that purpose, we use the G-I* statistics developed by Ord and Getis (1995) ${ }^{6}$. These statistics are computed for each region and they allow detecting the presence of local spatial autocorrelation: a positive value of this statistic for region $i$ indicates a spatial cluster of high values, whereas a negative value indicate a spatial clustering of low values around region $i$. Based on these statistics, we determine our spatial regimes, that can be interpreted as spatial convergence clubs, using the following rule: if the statistic for region $i$ is positive, then this region belongs to the group of "rich" regions and if the statistic for region $i$ is negative, then this region belongs to the group of "poor" regions.

For all weight matrices described above, we detect the presence of significant local spatial autocorrelation over the whole period. More precisely, two spatial regimes representative of the well-known core-periphery framework (Krugman 1991a, 1991b; Fujita et al., 1999), are persistent over the period and highlight some form of spatial heterogeneity. These regimes can be described as follows:

- 96 regions belong to the spatial regime "Core":

Belgium, Germany, Denmark, France, Italy (but Umbria, Marche, Lazio, Abruzzo, Molise, Campania, Puglia, Basilicata, Calabria, Sicilia, Sardegna), Luxembourg, the Netherlands, the United-Kingdom (but Northern-Ireland and Scotland).

- 49 regions belong to the spatial regime "Periphery":

Spain, Greece, Ireland, Southern Italy (Umbria, Marche, Lazio, Abruzzo, Molise, Campania, Puglia, Basilicata, Calabria, Sicilia, Sardegna), Portugal, the North of the United -Kingdom (Northern-Ireland and Scotland).

Note that this methodology differs from the one used by Baumont et al. (2003) that use LISA statistics (Anselin, 1995) to determine the spatial clubs. However, LISA statistics imply that the "atypical" regions must be dropped out of the sample. Baumont et al. (2003)

\footnotetext{
6 All computations in this section are carried out using the SpaceStat 1.91 software (Anselin, 1999).
} 
thus eliminate 3 regions. In our case however, this methodology would imply eliminating 9 regions. We therefore feel that the use of Getis-Ord statistics is more appropriate in order to be able to work with the entire sample.

The second step of our analysis consists in including the presence of both spatial effects in the estimation of the appropriate $\beta$-convergence model. Various tests aiming at detecting the presence of spatial effects have been described in Anselin (1988) and are applied here. Since the purpose of this paper is not to describe the successive steps leading to the detection of the most appropriate unconditional $\beta$-convergence model, we directly provide the result of our analysis in this section using the matrix $D(1)^{7}$. It appears that the most appropriate model specification is a spatial error model with groupwise heteroskedasticity and structural instability in the form of two regimes as previously described. The model can be described as follows:

$$
g_{T}=\alpha_{C} D_{C}+\beta_{C} D_{C} y_{0}+\alpha_{P} D_{P}+\beta_{P} D_{P} y_{0}+\varepsilon
$$

with $\varepsilon=\lambda W \varepsilon+u \quad$ and $\quad u \sim N\left(0,\left[\begin{array}{cc}\sigma_{\varepsilon, C}^{2} I_{96} & 0 \\ 0 & \sigma_{\varepsilon, P}^{2} I_{49}\end{array}\right]\right)$

where $g_{\tau}$ is the $(n \times 1)$ vector of average growth rates of per capita GDP between dates 0 and $T ; D_{C}$ and $D_{P}$ are dummy variables corresponding respectively to the core and periphery regimes previously defined; $\alpha_{C}, \alpha_{P}, \beta_{C}, \beta_{P}$ are unknown parameters to be estimated; $\lambda$ is a coefficient indicating the extent of spatial correlation between the residuals. Note that this specification assumes that spatial autocorrelation is identical between northern regions and between southern regions.

This type of specification takes into account the fact that the convergence process, if it exists, could be different within each of the regimes. The estimation results by Maximum

\footnotetext{
${ }^{7}$ All results are robust to the choice of the weight matrix and are available upon request from the authors.
} 
Likelihood (ML) estimation and Generalized Moments (GMM) estimation are displayed in table 1 .

$<<$ Insert table 1 here $>$

The results displayed in table 1 show that there is significant convergence among the regions belonging to the periphery regime ( $p$-value of 0.000 ) leading to a convergence speed of $3.15 \%$ for ML (3.28\% for GMM) and a half-life of 24 years (resp. 25 years). On the contrary, $\hat{\beta}_{C}$ does not have the expected sign and is not significant ( $p$-value greater than 0.6 ). Note that the Chow test of overall stability strongly rejects the joint null hypothesis. The individual coefficient stability tests reject the corresponding null hypotheses. The convergence process seems therefore to be quite different across regimes: if there is a convergence process among European regions, it mainly concerns the periphery regions but does not concern the northern regions. These last results confirm those found by Beine and Jean-Pierre (2000) using a sample of 62 NUTS 1 regions over the 1980-1995 period with an endogenous determination of convergence clubs. It is also consistent with the results obtained by Baumont et al. (2002) for a sample of 138 NUTS 2 regions over the same period.

The presence of spatial autocorrelation is confirmed by a highly significant and positive $\lambda$ coefficient. This specification implies spatial spillovers effects between the regions. They are illustrated in the following section. 


\section{Section 5 Spatial diffusion effects in European regions}

In this section, we analyse in more details the spatial diffusion property of the spatial error model discussed in section 3. Indeed, since $\varepsilon=\lambda W \varepsilon+u \Rightarrow \varepsilon=(I-\lambda W)^{-1} u$, model (4) can be written in the following form:

$$
g_{T}=\alpha_{C} D_{C}+\alpha_{P} D_{P}+\beta_{C} D_{C} y_{0}+\beta_{P} D_{P} y_{0}+(I-\lambda W)^{-1} u
$$

In this specification, a shock affecting one region propagates to all the other regions of the sample through the spatial transformation $(I-\lambda W)^{-1}$. We use this property to conduct a simulation experiment aimed at analysing the way shocks in the regions of the sample propagate to all the other regions.

Formally, let $a_{i}$ be the amount of the shock affecting region $i$ and $\hat{u}^{i}$ be the $(n \times 1)$ vector containing the estimated error of model (5) after a shock on error $i$ : $\hat{u}^{i \prime}=\left(\begin{array}{lllll}\hat{u}_{1} & \ldots & \hat{u}_{i}+a_{i} & \ldots & \hat{u}_{n}\end{array}\right)^{\prime}$. Therefore, the $(n \times 1)$ vector $y^{i^{*}}$ containing the observations on the simulated average growth rates of per capita GDP after a shock in region $i$ can be computed in the following way:

$$
y^{i^{*}}=X \hat{\gamma}+(I-\hat{\lambda} W)^{-1} \hat{u}^{i}
$$

where $X=\left[\begin{array}{llll}D_{C} & D_{P} & D_{C} y_{0} & D_{P} y_{0}\end{array}\right] ; \hat{\gamma}=\left[\begin{array}{llll}\hat{\alpha}_{C} & \hat{\alpha}_{P} & \hat{\beta}_{C} & \hat{\beta}_{P}\end{array}\right]^{\prime} ; \hat{\alpha}_{C}, \hat{\alpha}_{P}, \hat{\beta}_{C}, \hat{\beta}_{P}$ and $\hat{\lambda}$ are the ML estimations of $\alpha_{C}, \alpha_{P}, \beta_{C}, \beta_{p}$ and $\lambda$ in the spatial error model (4). Let $Y^{*}$ be the 
matrix of dimension $(n \times n)$ containing the observations on the simulated average growth rates of per capita GDP after a shock in each region:

$$
Y^{*}=\left[\begin{array}{lll}
y^{1^{*}} & \ldots & y^{n^{*}}
\end{array}\right]=\left[\begin{array}{lll}
X \hat{\gamma} & \ldots & X \hat{\gamma}
\end{array}\right]+A^{-1}\left[\begin{array}{lll}
\hat{u}^{1} & \ldots & \hat{u}^{n}
\end{array}\right]
$$

with $A=I-\hat{\lambda} W$. Equation (7) can also be rewritten in a more compact way:

$$
Y^{*}=S^{\prime} \otimes X \hat{\gamma}+A^{-1} \hat{U}
$$

where $\otimes$ is the Kronecker product; $\hat{U}$ is the matrix of dimension $(n \times n)$ defined as: $\hat{U}=\left[\begin{array}{lll}\hat{u}^{1} & \ldots & \hat{u}^{n}\end{array}\right]$. Given the definition of each element $\hat{u}^{i}$, this matrix $\hat{U}$ can also be written as:

$$
\hat{U}=\left(\begin{array}{cccc}
\hat{u}_{1}+a_{1} & \hat{u}_{1} & \ldots & \hat{u}_{1} \\
\hat{u}_{2} & \hat{u}_{2}+a_{2} & \ldots & \hat{u}_{2} \\
\vdots & \vdots & \ddots & \vdots \\
\hat{u}_{n} & \hat{u}_{n} & \ldots & \hat{u}_{n}+a_{n}
\end{array}\right) \Rightarrow \hat{U}=S^{\prime} \otimes \hat{u}+\operatorname{diag}\left(a_{i}\right)
$$

Combining (8) and (9), we obtain:

$$
Y^{*}=S^{\prime} \otimes X \hat{\gamma}+A^{-1}\left(S^{\prime} \otimes \hat{u}+\operatorname{diag}\left(a_{i}\right)\right)
$$

This expression yields a matrix of dimension $(n \times n)$ where the column $i$ indicates the simulated average growth rates of capita GDP for all regions in the sample after a shock in region $i$. To further evaluate the impact of these shocks on the average growth rates of the regions in our sample, we first compute the difference $D$ between the matrix of simulated average growth rates $Y^{*}$ (after the shock) and the matrix of actual average growth rates $Y$ (without shock): $D=Y^{*}-Y$. Since $Y=S^{\prime} \otimes y$, with $y=X \hat{\gamma}+A^{-1} \hat{u}$, then :

$$
D=A^{-1} \operatorname{diag}\left(a_{i}\right) \quad \text { with } A=I-\hat{\lambda} W
$$


Second, we consider the matrix $V$, containing the variation in percentage between the simulated and the actual average growth rates. $V$ is obtained by dividing each term of the $D$ matrix by each corresponding term of the $Y$ matrix. On the one hand, the elements on the main diagonal represent the impact of a shock in a region on itself. On the other hand, the other elements in each column $i$ of the matrix $V$ indicates the how the region $i$ affects the other regions of the sample when there is a shock in this region (emission).

This methodology in fact extends the one developed in Le Gallo et al. (2003), where all shocks are set equal to twice the residual standard error of the estimated spatial error model. Using a sample of 138 regions over the 1980-1995 regions, they show that the strength of the diffusion both depends on the localisation and the economic dynamism: rich regions located in the core diffuse more the poor regions in the periphery. In this paper, rather than considering equal random shocks, we include the real values of per capita structural funds over 1989-1999. Note however that in this methodology the simulation is carried out on the 1989-1999 growth rates that already include the effect of structural funds. In that purpose, we want to study whether allowing for differentiated shocks offsets the effects of economic dynamism and relative localisation.

We consider two different $\operatorname{cases}^{8}$. In the first one, each region experiences a similar shock proportional to average amount of per capita structural funds distributed during the 1989-1999 period. In the second one, each region experiences a different shock proportional to the amount of structural funds it has received during the period. Figures 3 and 4 display the main diagonal of $V$ that represents the impacts of the shocks on the region itself. In the case of an equal shock, the extent of the impact does not vary much from one region to another. In the case of differentiated shocks (figure 4), the extent of the impact on the targeted regions

\footnotetext{
8 The codes used to carry out the simulations in this section have been developed using Python 2.2 (http://www.python.org).
} 
increases very much, and more especially in the peripheral regions, since they receive the largest amounts of structural funds. We note however that the extent of the impact increases the least in Alentejo and Algarve (Portugal) and in Kentriki Makedonia, Kriti, Peloponnisos, Dytiki Ellada (Greece), considering that Community assistance was respectively $2.7,1.8$ times greater than the average amount of structural funds for the Portuguese regions and respectively $1.6,2.6,1.8,1.7$ times for the Greek regions. These results tend to demonstrate that the greater cohesion efforts allocated to these regions have not been sufficient enough to favor growth in these particular regions. This may be due to the peripherality of these regions or the lack of efficiency of financed infrastructures to favor cohesion, as depicted in section 2.

To capture the extent of spillover effects, we analyse the diffusion properties of a shock in each single region to all the other regions in figures 5 and 6 . It corresponds to the computed median for each column of $V$, excluding the main diagonal. As in Le Gallo et al. (2003) when the shocks are equal (figure 5), it appears that the most influential regions are rich northern European regions mainly belonging to Belgium, Germany, Netherlands and France; Luxembourg is also highly influential. All these regions belong to the core of Europe. On the contrary, poor southern Objective 1 regions are the less influential. When the shocks are differentiated (figure 6), the overall picture is not really modified: the most influential regions are still located in the core and are less numerous than in the previous case. The diffusion properties of the peripheral regions have not increased, which can be explained by the fact that core regions are more connected with each other in terms of accessibility via transportation network. They are centrally located and much smaller regions also, which facilitates interregional dependences. Finally, the economic structure of core regions is more homogeneous than the one of peripheral regions. This result suggests also that the small extent of spillover effects in peripheral regions could be a relevant explanation of their backwardness, and that even greater targeted funds do not allow to favor spillovers in 
periphery. This tends to confirm the results of section 2 which emphasize that gains in accessibility are greater in the core than in periphery when structural funds come to a decrease in interregional transportation costs.

\section{Section 6 Conclusion}

The aim of this paper has been to highlighting the impact of structural funds on the convergence process of 145 European regions over the 1989-1999 period. If these funds are mainly devoted to the least developed regions, the persistence of regional inequalities over the period leads to a real reconsideration of their efficiency. Since the majority of these funds finance transportation infrastructures which induce industry relocation effects, their impact on regional development is not clear yet but surely needs to be seen in the light of spillover effects their spatial allocation implies. In other words, estimating the impact of structural funds on regional growth without including the presence of significant spatial effects would lead to unreliable results.

In order to include spatial effects in the determination of the most appropriate $\beta$ convergence model, we start by using the Getis-Ord statistics. The results display the presence of significant local spatial autocorrelation in the form of two regimes representative of the well-known core-periphery pattern over the whole period (Krugman 1991a, 1991b; Fujita et al., 1999). Various tests aiming at including the significant presence of spatial effects in our model lead us to consider a spatial error model with groupwise heteroskedasticity and structural instability in the form of the two regimes previously detected. In this model, spatial correlation in the residuals implies that a shock in a given region propagates to all regions of the sample. We therefore use this property to estimate the impact of a shock proportional to per capita structural funds on the growth rate of the targeted region first, and then on the growth rate of all the other region of our sample. Simulation 
experiments perform the analysis when the extent of shocks corresponds first to the mean per capita structural funds for all the regions (equal shock), and second when it corresponds to the real value of per capita structural funds for each region (differentiated shock). The results show that in the case of an equal shock, the extent of the impact on regional growth does not vary much from one region to another. In the case of differentiated shocks, the extent of the impact on the peripheral regions increases very much, traducing that they are the main beneficiaries of these funds. However the extent of the impact does not increase much in Alentejo and Algarve (Portugal), Kentriki Makedonia, Kriti, Peloponnisos, Dytiki Ellada (Greece). This may be due to the peripherality of these regions and implies that greater cohesion efforts are necessary for these regions. When it comes to measuring spillover effects through the impact of the funds targeted in one region on the growth rate of all the other regions, the results detect the presence of a growth diffusion process only from the core regions, whatever the extent of the shock is (either equal or differentiated). This may reflect that core region are generally smaller and more connected with each other, through trade and transport network, than peripheral regions. This result suggests also that the small extent of spillover effects in peripheral regions could be an explanation of their backwardness, and that even greater targeted funds do not allow to favor spillovers in periphery. It should be noted however that the empirical findings, while supporting the expectations advanced by the theory, may in part result from the particular nature of the modelling formulations we used. In this regards, further works examining the consistency of the nature and the extent of spillover effects would need to be undertaken. 


\section{References}

Anselin L. (1988) Spatial Econometrics: Methods and Models, Dordrecht: Kluwer Academic Publishers.

Anselin L. (1996) The Moran Scatterplot as an ESDA Tool to Assess Local Instability in Spatial Association, in: Fisher M., Scholten H.J. and Unwin D. (Eds), Spatial Analytical Perspectives on GIS in Environmental and Socio-Economic Sciences, London: Taylor and Francis.

Anselin, L. (1999) SpaceStat, a Software Package for the Analysis of Spatial Data, Version 1.90, Ann Arbor, BioMedware.

Anselin L. (2001) Spatial Econometrics, in: Baltagi B. (Ed.), Companion to Econometrics, Oxford, Basil Blackwell.

Anselin L. and Bera A. (1998) Spatial Dependence in Linear Regression Models with an Introduction to Spatial Econometrics, in: Ullah A. and Giles D.E.A. (Eds.), Handbook of Applied Economic Statistics, Berlin:Springer-Verlag.

Anselin L. and Cho W.K.T. (2000) Spatial Effects and Ecological Inference, Political Analysis, 10, 276-297.

Armstrong H. (1995) Convergence among the Regions of the European Union, Papers in Regional Science, 74, 143-152.

Arbia G. (1989) Spatial Data Configuration in Statistical Analysis of Regional Economic and Related Problems, Boston: Kluwer Academic Publishers.

Aschauer D. (1989) Is Public Infrastructure Productive?, Journal of Monetary Economics, 23, 177-200.

Baumol W.J. (1986) Productivity Growth, Convergence and Welfare: What the Long Run Data Show, American Economic Review, 76, 1072-1085.

Baumont C., Ertur C. and Le Gallo J. (2003) Spatial Convergence Clubs and the European Growth Process, 1980-1995, in: Fingleton B. (Ed.), European Regional Growth, Berlin: Springer, forthcoming.

Barro R. J. (1990) Government Spending in a Simple Model of Endogenous Growth, Journal of Political Economy, 98, 103-125.

Barro R.J. and Sala-I-Martin X. (1991) Convergence across States and Regions, Brookings Papers on Economic Activity, 1991, 107-182.

Barro R.J. and Sala-I-Martin X. (1992) Convergence, Journal of Political Economy, 100, 223 251.

Barro R.J. and Sala-I-Martin X. (1995) Economic Growth Theory, Boston: McGraw-Hill.

Berthélemy J.-C. and Varoudakis A. (1996) Economic Growth, Convergence Clubs, and the Role of Financial Development, Oxford Economic Papers, 48, 300-328.

Bivand R.S. and Brunstad R.J. (2002), Regional Growth in Western Europe: an Empirical Exploration of Interactions with Agriculture and Agricultural Policy, Discussion Paper 01/02, Norwegian School of Economics and Business Administration.

Boldrin M. and Canova F. (2001) Europe's Regions, Income Disparities and Regional Policies, Economic Policy, 32, 207-253.

Chatterji M. (1992) Convergence Clubs and Endogenous Growth, Oxford Review of Economic Policy, 8, 57-69.

Dall'erba S. (2003a) Competition, Complementarity and Increasing Disparities Among the Regions of Spain and Portugal, Discussion Paper REAL 03-T-04, University of Illinois at Urbana-Champaign.

Dall'erba S. (2003b) Distribution of Regional Income and Regional Funds in Europe 19891999: an Exploratory Spatial Data Analysis, Discussion Paper REAL 03-T-01, University of Illinois at Urbana-Champaign. 
Dall'erba S. and Hewings G.J.D. (2003) European Regional Development Policies: the Tradeoff Between Efficiency-Equity Revisited, Discussion Paper REAL 03-T-02, University of Illinois at Urbana-Champaign.

De Long B.J. and Summers L.H. (1991) Equipment Investment and Economic Growth, Quarterly Journal of Economics, 106, 445-502.

Durlauf S.N. and Johnson P.A. (1995) Multiple Regimes and Cross-Country Growth Behaviour. Journal of Applied Econometrics, 10, 365-384.

Durlauf S.N. and Quah D. (1999) The New Empirics of Economic Growth, in: Taylor J. and Woodford M. (Eds), Handbook of Macroeconomics, North-Holland Elsevier Science.

Esteban J-M. (1994) La Desigualdad Interregional en Europa y en Espana: Descripcion y Analisis, in: Crecimiento y Convergencia Regional en Espana y en Europa, II, IAE, Barcelona.

European Commission (1992) “Community Structural Interventions", Statistical report $n{ }^{\circ}$, July.

European Commission (1992) "Community Structural Interventions", Statistical report $n^{\circ} 4$, December.

European Commission (1999) Sixth Periodic Report on the Social and Economic Situation and Development of the Regions of the Community, Brussels, Commission of the European Communities, February.

Fingleton B. (1999) Estimates of Time to Economic Convergence: an Analysis of Regions of the European Union, International Regional Science Review, 22, 5-34.

Fingleton B. (2001) Equilibrium and Economic Growth: Spatial Econometric Models and simulations, Journal of Regional Science, 41, 117-147.

Fingleton B. (2003) Regional Economic Growth and Convergence: Insights from a Spatial Econometric Perspective, in: Anselin L., Florax R.J.G.M. and Rey S.J., Advances in Spatial Econometrics, Berlin: Springer, forthcoming.

Friedman M. (1992) Do Old Fallacies ever Die?, Journal of Economic Literature, 30, 2129 2132.

Fujita M., Krugman P. and Venables A.J. (1999) The Spatial Economy, Cambridge: MIT Press.

Krugman P. (1991a) Geography and Trade, Cambridge MA: MIT Press.

Krugman P. (1991b) Increasing Returns and Economic Geography, Journal of Political Economy, 99, 483-499.

Krugman P. and Venables A. (1995) Globalization and the Inequality of Nations, Quarterly Journal of Economics, 110, 715-756.

Krugman P. and Venables A. (1996) Integration, Specialization, and Adjustment, European Economic Review, 40, 959-967.

Le Gallo J. and Ertur C. (2003) Exploratory Spatial Data Analysis of the Distribution of Regional per capita GDP in Europe, 1980-1995, Papers in Regional Science, forthcoming.

Le Gallo J., Ertur C. and Baumont C. (2003) A Spatial Econometric Analysis of Convergence across European Regions, 1980-1995, in: Fingleton B. (Ed.), European Regional Growth, Berlin: Springer, forthcoming.

Lopez-Bazo E., Vayà E., Mora A.J. and Suriñach J. (1999) Regional Economic Dynamics and Convergence in the European Union, Annals of Regional Science, 33, 343-370.

Mankiw N.G. (1995) The Growth of Nations, Brookings Papers on Economic Activity, 1, 275-326.

Martin P. (1999) Public Policies, Regional Inequalities and Growth, Journal of Public Economics, 73, 85-105.

Martin P. (2000), The Role of Public Policy in the Process of Regional Convergence, EIB Papers, 5 (2), 69-79. 
Martin P. and Ottaviano G.I.P.(1999) Growing Locations: Industry Location in a Model of Endogenous Growth, European Economic Review, 43, 281-302.

Maurseth P.B. (2001) Convergence, Geography and Technology, Structural Change and Economic Dynamics, 12, 247-276.

Moreno R. and Trehan B. (1997) Location and the Growth of Nations, Journal of Economic Growth, 2, 399-418.

Neven D. and Gouyette C. (1995) Regional Convergence in the European Community, Journal of Common Market Studies, 33, 47-65.

Ord J.K. and Getis A. (1995) Local Spatial Autocorrelation Statistics: Distributional Issues and an Application, Geographical Analysis, 27, 286-305.

Puga D. (1999) The Rise and Fall of Regional Inequalities, European Economic Review, 43, 303-334.

Puga D. and Venables A. J. (1997) Preferential Trading Arrangements and Industrial Location, Journal of International Economics, 43, 347-368.

Quah D. (1993) Galton's Fallacy and Tests of the Convergence Hypothesis, Scandinavian Journal of Economics, 95, 427-443.

Quah D. (1996) Regional Convergence Clusters across Europe, European Economic Review, 40, 1951-1958.

Rey S. and Montouri B. (1999) US Regional Income Convergence: a Spatial Econometric Perspective, Regional Studies, 33, 143-156.

Temple J. (1999) The New Growth Evidence, Journal of Economic Literature, 37, 112- 156.

Venables A. and Gasiorek M. (1999) Evaluating Regional Infrastructure: a Computable Equilibrium Approach, in Study of the Socio-economic Impact of the Projects Financed by the Cohesion Fund - A Modelling Approach, vol. 2. Luxembourg: Office for Official Publications of the European Communities.

Vickerman R.W. (1996), Location, Accessibility and Regional Development: the Appraisal of Trans-European Networks, Transport Policy, 2, 225-234.

Vickerman R., Spiekermann K. and Wegner M. (1999) Accessibility and Economic Development in Europe, Regional Studies, 33, 1-15. 
Table 1: Estimation results for the spatial error model with groupwise heteroskedasticity and structural instability (weight matrix: dis1)

\begin{tabular}{|c|c|c|c|c|c|c|}
\hline \multicolumn{4}{|c|}{ Estimation results } & \multicolumn{3}{|c|}{ Tests } \\
\hline & Core & \multicolumn{2}{|c|}{ Periphery } & & ML & GMM \\
\hline & ML GMM & $\mathbf{M L}$ & GMM & Chow-Wald & $\begin{array}{l}12.873 \\
(0.002)\end{array}$ & $\begin{array}{l}13.615 \\
(0.001)\end{array}$ \\
\hline$\hat{\alpha}_{r}$ & $\begin{array}{cc}0.025 & 0.028 \\
(0.474) & (0.424) \\
\end{array}$ & $\begin{array}{c}0.293 \\
(0.000) \\
\end{array}$ & $\begin{array}{c}0.303 \\
(0.000)\end{array}$ & $\begin{array}{l}\text { Ind. stability test on } \\
\text { alpha }\end{array}$ & $\begin{array}{l}11.743 \\
(0.000)\end{array}$ & $\begin{array}{l}12.707 \\
(0.000)\end{array}$ \\
\hline$\hat{\beta}_{r}$ & $\begin{array}{cc}0.001 & 0.001 \\
(0.667) & (0.730)\end{array}$ & $\begin{array}{l}-0.027 \\
(0.000)\end{array}$ & $\begin{array}{l}-0.028 \\
(0.000)\end{array}$ & $\begin{array}{l}\text { Ind. stability test on } \\
\text { beta }\end{array}$ & $\begin{array}{l}11.044 \\
(0.000)\end{array}$ & $\begin{array}{l}12.122 \\
(0.000)\end{array}$ \\
\hline$\hat{\lambda}$ & \multicolumn{3}{|c|}{$\begin{array}{ll}0.748(\mathrm{ML}) & 0.705(\mathrm{GMM}) \\
(0.000) & \end{array}$} & $\begin{array}{l}\text { LR test on groupwise } \\
\text { heteroskedasticity }\end{array}$ & $\begin{array}{l}24.687 \\
(0.000)\end{array}$ & - \\
\hline $\begin{array}{c}\text { Convergence } \\
\text { speed }\end{array}$ & - & $3.15 \%$ & $3.28 \%$ & & & \\
\hline Half-life & $-\quad-$ & 25 & 24 & & & \\
\hline Sq. Corr. & $0.351 \quad(\mathrm{ML})$ & 0.360 & (GM) & & & \\
\hline LIK & \multicolumn{3}{|c|}{499.927} & & & \\
\hline AIC & \multicolumn{3}{|c|}{-991.854} & & & \\
\hline SC & \multicolumn{3}{|c|}{-979.947} & & & \\
\hline$\sigma_{\varepsilon, P}^{2}$ & \multicolumn{3}{|c|}{$\begin{array}{l}9.942 .10^{-5}(\mathrm{ML}) 1.020 .10^{-5}(\mathrm{GMM}) \\
(0.000)\end{array}$} & & & \\
\hline$\sigma_{\varepsilon, C}^{2}$ & \multicolumn{3}{|c|}{$\begin{array}{l}4.552 .10^{-5}(\mathrm{ML}) 4.619 .10^{-5}(\mathrm{GMM}) \\
(0.000)\end{array}$} & & & \\
\hline
\end{tabular}

Notes: $p$-values are in brackets. $M L$ indicates maximum likelihood estimation. $G M M$ indicates iterated generalized moments estimation (Kelejian and Prucha 1999). Sq. Corr. is the squared correlation between predicted values and actual values. $L I K$ is value of the maximum likelihood function. $A I C$ is the Akaike (1974) information criterion. $S C$ is the Schwarz information criterion (1978). The individual coefficient stability tests are based on spatially adjusted asymptotic Wald statistics, distributed as $\chi^{2}$ with 1 degree of freedom. The Chow - Wald test of overall stability is also based on a spatially adjusted asymptotic Wald statistic, distributed as $\chi^{2}$ with 2 degrees of freedom (Anselin 1988). 


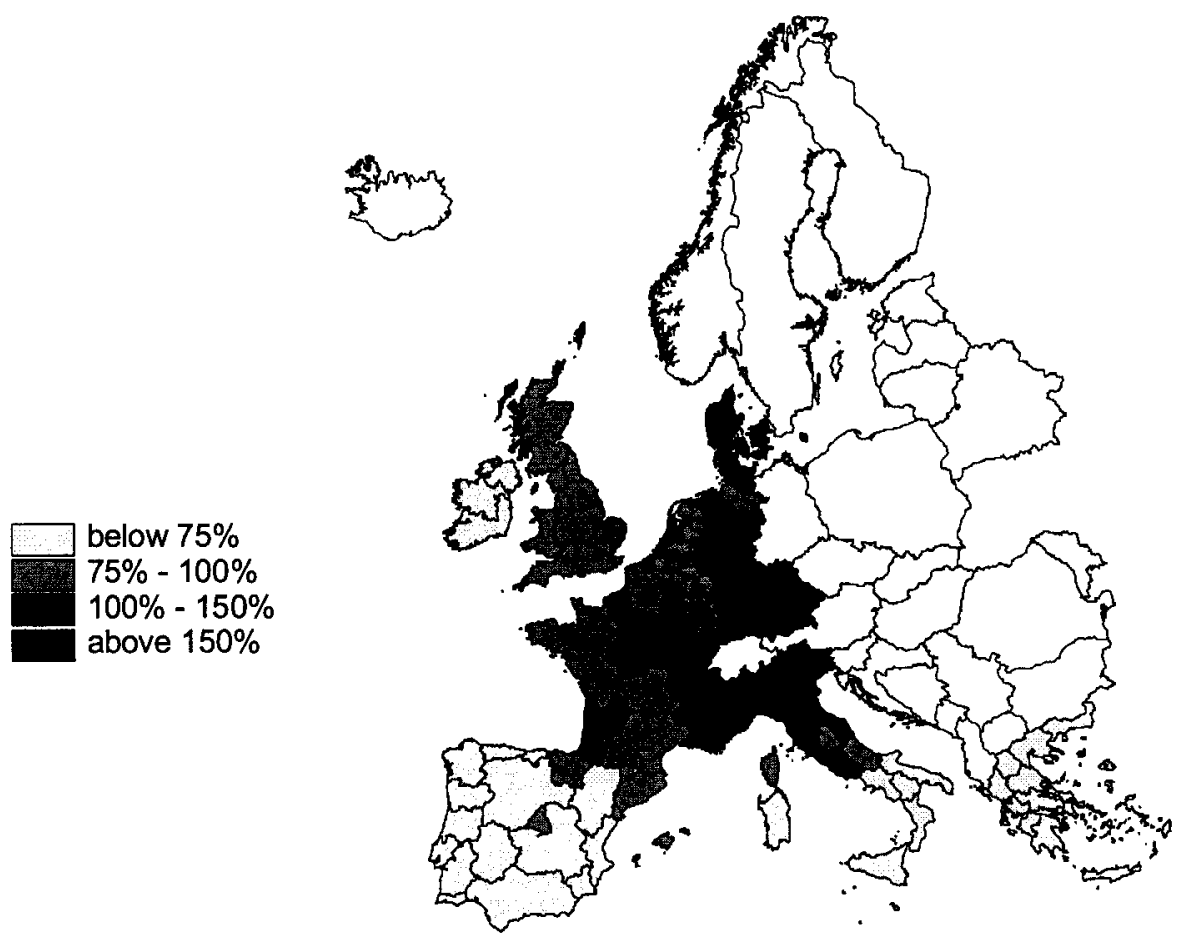

Figure 1: GDP per capita relative to the European average in 1989

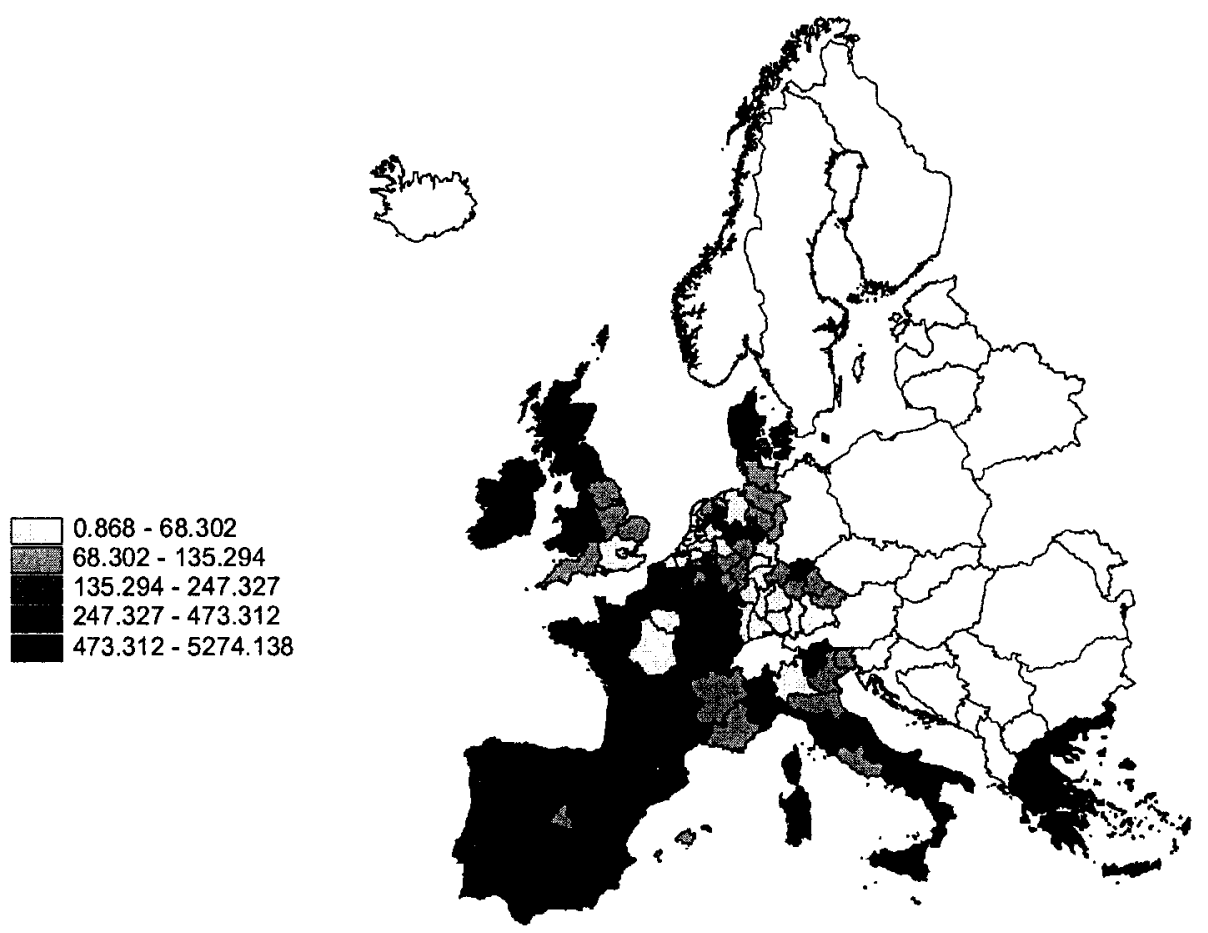

Figure 2: Spatial distribution of regional funds during 1989-1999 
$0.007-0.013$

$0.013-0.017$

$0.017-0.02$

$0.02-0.024$

$0.024-0.031$

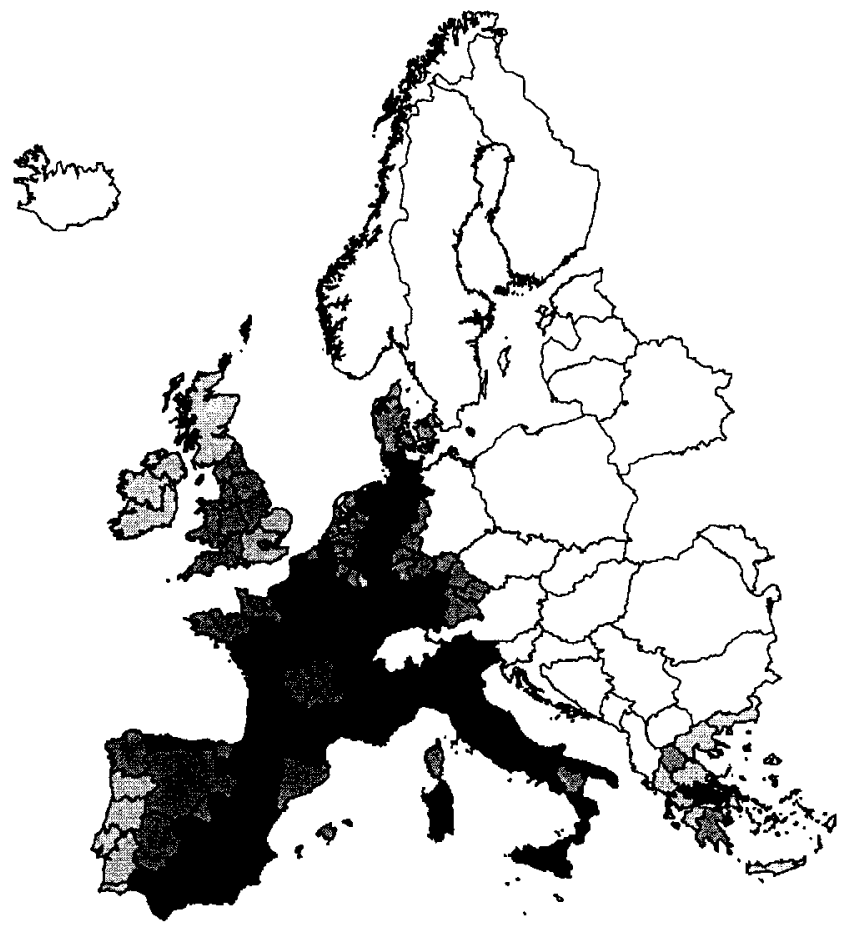

Figure 3: Impact of an equal shock on each region's growth

$0-0.012$

$0.012-0.033$

$0.033-0.061$

$0.061-0.1$

$0.1-0.182$

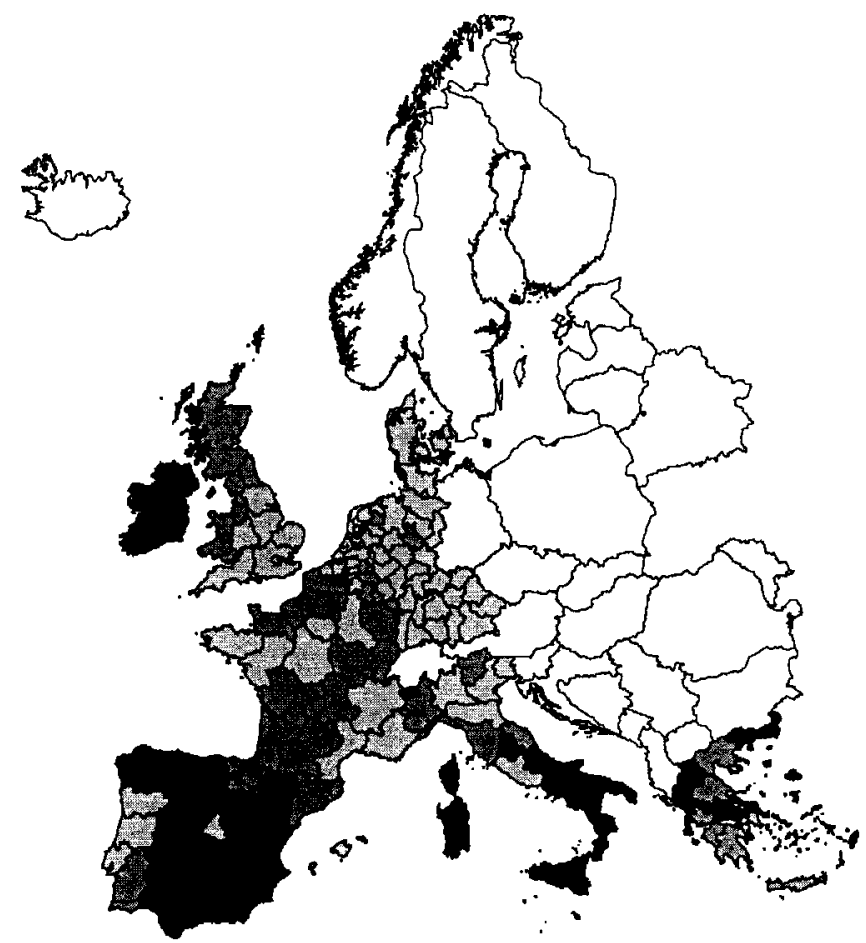

Figure 4: Impact of differentiated shocks on each region's growth 
$0-0.000011$

$0.000011-0.000029$

$0.000029-0.000052$

$0.000052-0.000121$

$0.000121-0.000351$

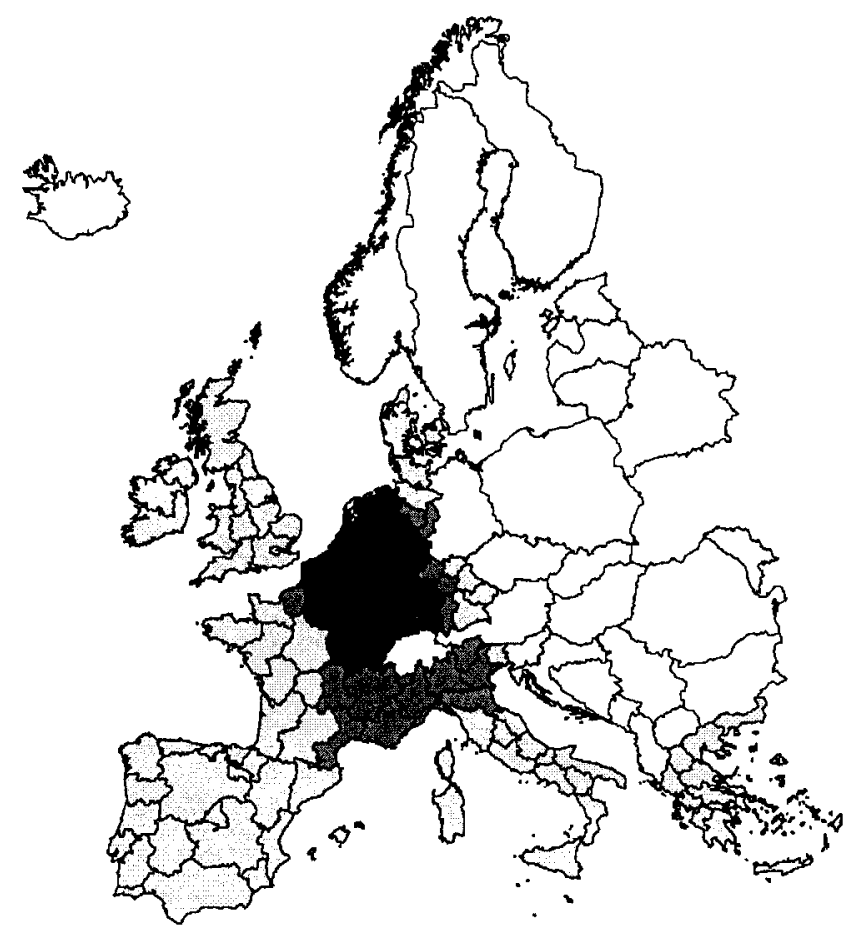

Figure 5: Distribution of the regions according to the extent of spillover effects they produce with an equal shock

0.000011

$0.000011-0.000029$

$0.000029-0.000052$

$0.000052-0.000121$

$0.000121-0.000351$

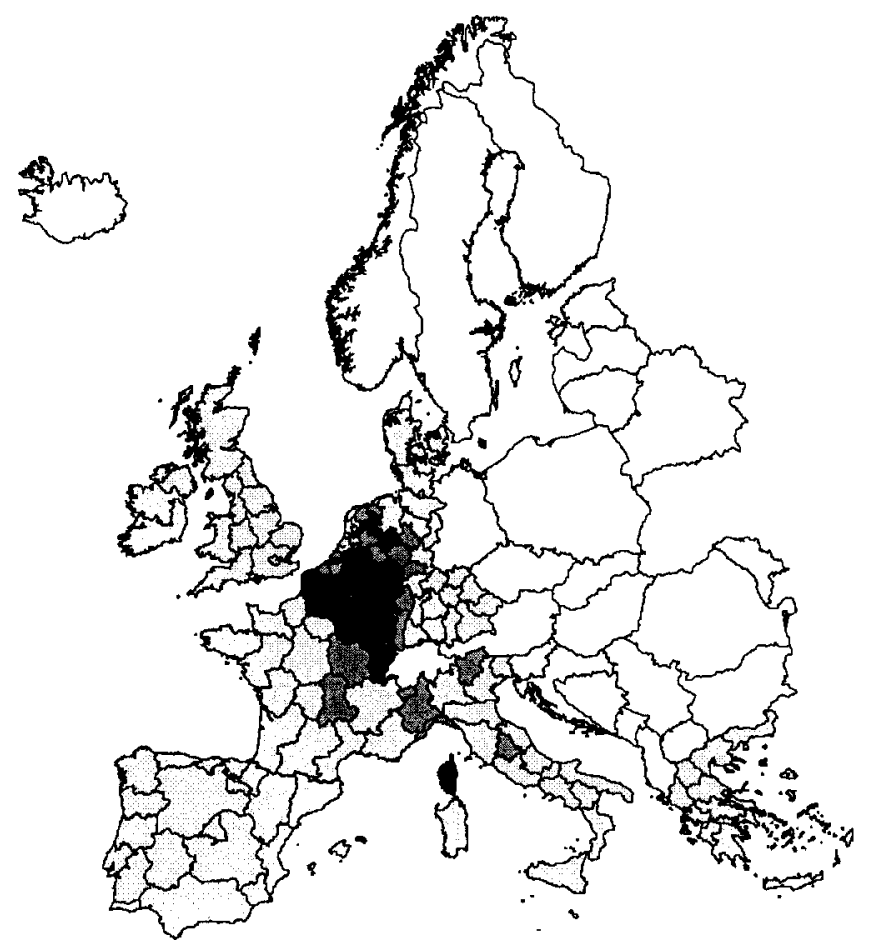

Figure 6: Distribution of the regions according to the extent of spillover effects they produce with differentiated shocks 